\title{
XXVI. Remarks upon chloranil
}

\section{Augustus William Hofmann Ph.D.}

To cite this article: Augustus William Hofmann Ph.D. (1845) XXVI. Remarks upon chloranil , Philosophical Magazine Series 3, 26:172, 199-206, DOI: 10.1080/14786444508645105

To link to this article: http://dx.doi.org/10.1080/14786444508645105

册 Published online: 30 Apr 2009.

Submit your article to this journal 준

Џll Article views: 2

Q View related articles $₫$ 
it changes from a yellow to a bright green colour. The distillation need not be long continued, as the kinone is very volatile, and comes nearly all over at the first. I have tried this experiment with the genuine barks China rubra, China loxa, and China regia, and detected the kinic acid very readily, when less than a quarter of an ounce of each was employed. I have also operated on two ounces of the false bark, China nova Surinamensis, but was unable to detect the least trace of kinic acid.

It has long been stated in most systems of chemistry, on the authority of Berzelius, that the alburnum of Pinus sylvestris contains a half per cent. of kinate of lime, and that kinic acid exists along with gallic acid in the barks of various other trees. A pound and a half of the inner bark and alburnum of the Pinus sylvestris was treated in the way already described, but I was unable to detect any trace of kinic acid; though on adding less than two grains of kinate of lime the presence of kinone in the liquid which distilled over was immediately perceptible.

I may state, in conclusion, that the presence of the vegetable alkaloids quinine or cinchonine in a bark may be readily detected by the following simple experiment. Macerate the bark with dilute sulphuric acid and precipitate with a slight excess of carbonate of soda or potash. Collect the dark-coloured, very impure precipitate, and distil it with a great excess of caustic soda or potash, cincholin will distil over in oily drops if the bark has contained either of these vegetable alkaloids. Cincholin is easily recognisable by its peculiar taste and smell and its strongly-marked alkaline properties. It is nearly insoluble in water, unless first neutralized by an acid, when it readily dissolves; but it is immediately reprecipitated in oily drops on the addition of an alkali. It is quite true that the production of cincholin is not a decisive proof that a bark must necessarily contain quinine or cinchonine, as other alkaloids, such for instance as strychnine, also yield it when distilled with potash. The production of cincholin, however, clearly indicates the existence of at least one alkaloid in the bark, the exact nature of which may be subsequently ascertained by the usual methods.

XXVI. Remarks upon Chloranil.

By Augustus William Hofmann, Ph.D.*

GRMANN + , in his researches upon the action of chlorine on indigo, obtained, as the last product of this reaction, a

* Communicated by the Chemical Society; having been read December 2,1844 .

+ Journ. für Pralt. Chem., Bd, xxii. S. 279. [Phil. Mag. S. 3, vol, xix. p. 192.] 
crystalline body free from hydrogen, to which he gave the name chloranil. This substance, remarkable on account of the series of interesting transformations which it undergoes when in contact with the alkalies, has been diligently studied by Erdmann. From his experiments, the composition of chloranil is represented by the formula-

$$
\mathrm{C}_{6} \mathrm{Cl}_{2} \mathrm{O}_{2} \text {. }
$$

This body has lately become the starting -point of some interesting discussions, which Laurent* brought before the Academy at Paris. The view of this chemist assumes the equivalent of chloranil to be double, agreeing with the formula,-

$$
\mathrm{C}_{12} \mathrm{Cl}_{4} \mathrm{O}_{4} \text {. }
$$

'The method which Erdmann employed for obtaining chloranil is circuitous, and yields very little of that substance. He passed a stream of chlorine gas through an alcoholic solution of chlorisatin or bichlorisatin. 'The following equation represents the transformation of the chlorisatin into chloranil :-

$$
\underbrace{\mathrm{C}_{16}\left\{\begin{array}{l}
\mathrm{H}_{4} \\
\mathrm{Cl}
\end{array}\right\} \mathrm{NO}_{4}}_{\text {Chlorisatin. }}+8 \mathrm{O}+4 \mathrm{Cl}=\underbrace{\mathrm{C}_{12} \mathrm{Cl}_{4} \mathrm{O}_{4}}_{\text {Chloranil. }}+4 \mathrm{CO}_{2}+\mathrm{NH}_{3}+\mathrm{HCl} \text {. }
$$

The process is not, however, so simple, as there is formed at the same time chlorinated chlorindoptic acid (Laurent's chlorophenussic acid $\dagger$ ), as well as many other secondary products, and there is obtained a comparatively small quantity only of chloranil.

Somewhat later chloranil was re-observed under other circumstances. Fritzche $\ddagger$ found, in some experiments upon the blue colour assumed by aniline from the action of the oxygen compounds of chlorine, that by a continued digestion of a mixture of chlorate of potash and hydrochloric acid upon aniline, chloranil is also formed.

I have had the opportunity, in a research upon the organic bases of coal-gas naphthas, to confirm this statement; the whole of the carbon of the aniline enters into the chloranil, as the following equation shows:-

$$
\underbrace{\mathrm{C}_{12} \mathrm{H}_{7} \mathrm{~N}}_{\text {Aniline. }}, 4 \mathrm{O}+8 \mathrm{Cl}=\underbrace{\mathrm{C}_{12} \mathrm{H}_{4} \mathrm{O}_{4}}_{\text {Chloranil. }}+\mathrm{NH}_{3}+4 \mathrm{HCl} \text {. }
$$

The close relation subsisting between the aniline and phe. nyle series induced me to try whether chloranil could not be obtained from different members of this group of bodies. I soon learnt that chloranil is often formed, as the last product of decomposition of organic bodies, under the

* Conptes Rendus, t. xix. No. 6. S. 316.

† Ann. de Chem. et de Phys., 3me ser. t. iii. p. 498. [Plil. Mag. S. 3. vol. xix. p. 191.]

$\ddagger$ Bullet. Scient. de St. Pétersb., 1843, t. i. p. 103.

\$ Philosophical Magazine, Third Series, vol, xxiv. p. 199. 
united influence of oxygen and chlorine. I commenced my investigation with the hydrate of phenyle, and selected as a means of oxidation a mixture of hydrochloric acid and chlorate of potash, in which oxygen and chlorine are disposable. When hydrate of phenyle in a porcelain basin is treated with strong hydrochloric acid, and there is added at intervals small crystals of chlorate of potash, a violent reaction ensues, and the colourless oil acquires a reddish-brown colour and inspissates. If the action has lasted sufficiently long, the whole mass changes to a light yellow crystalline matter, which is no other than chloranil. As it takes a long time to ensure perfect decomposition, it is advisable towards the end of the process to apply heat, in order to promote the action. I have endeavoured to shorten the time by employing an alcoholic solution of hydrate of phenyle; the decomposition then takes place indeed quicker, but a great quantity of chlorate of potash is wasted by the conversion of the alcohol into acetic æther. When alcohol is used, the addition of strong hydrochloric acid, or too quick an introduction of large quantities of chlorate of potash must be avoided, as the mass inflames readily with explosion. 'These explosions even sometimes take place when no alcohol has been added; it is therefore always advantageous to conduct the operation in basins.

If a boiling saturated aqueous solution of hydrate of phenyle is employed it saves time, and also chlorate of potash; or a watery extract of coal-gas naphtha may be at once taken, as it contains aniline and hydrate of phenyle, both being convertible into chloranil. The produce is in this way, however, very limited, owing to the slight solubility of these two compounds in water*.

To purify the chloranil it is only necessary to affuse with water, which dissolves any adhering chloride of potassium, and to crystallize from alcohol. This menstruum dissolves the chloranil with difficulty in the heat; and on cooling the whole deposits.

I have compared minutely the properties of the substance obtained in this way with those given by Erdmann in his treatise on chloranil, and find that they agree perfectly. The body I procured from hydrate of phenyle, as was betore remarked, is insoluble in water, dissolved with difficulty by alcohol, but more easily by æther, and crystallizes from the two latter solvents in shining golden-yellow plates; the motherliquor assumes a violet tint when exposed to the air. It begins

* In an experiment where I treated the coal-gas naphtha with the oxidizing mixture there was no chloranil found, apparently owing to its quantity being so minute when compared with that of the other products.

Phil. Mag. S. 3. Vol. 26. No. 172. March 1845. P 
to volatilize at $302^{\circ} \mathrm{F}$, and between $410-428^{\circ} \mathrm{F}$. the sublimation is rapid; if it be heated above this temperature it melts, and is finally carbonized. The sublimate has the appearance of an extremely soft, light, iridescent powder, which remains intact with acids, but when treated with alkalies is changed with the greatest facility. When the crystals are drenched with a dilute potash-ley, they acquire immediately a dark colour with a shade of green, but on the application of heat dissolve to a blood-red fluid, from which purple needles of an organic salt are deposited upon cooling. These needles, when immersed in dilute hydrochloric acid, assume, without altering their form, a bright red colour. They are quite insoluble in very dilute acids, but dissolve in pure water with a beautiful violet hue. By the addition of hydrochloric acid the liquid is discoloured immediately, and after some time the red crystals again deposit.

There can be no doubt from the foregoing that the substance obtained from the hydrate of phenyle and Erdmann's chloranil are identical. I have notwithstanding made some combustions of this compound. The analyses were however made with a product which was only recrystallized from alcohol, and not sublimed; the substance was therefore not quite pure, a circumstance which Erdmann had found previously. In five analyses this chemist always obtained a constant excess of carbon: my analyses were also encumbered with the same fault, owing to which there is a discrepancy between the chlorine found and that of theory.

I. $0.5845 \mathrm{grm}$. of substance ignited with chromate of lead, gave 0.6474 grm. of carbonic acid and $0.0212 \mathrm{grm}$. water.

II. $0.4615 \mathrm{grm}$. of substance ignited with chromate of lead, gave $0.5090 \mathrm{grm}$. of carbonic acid and $0.0120 \mathrm{grm}$. water.

III. $0.2555 \mathrm{grm}$. of substance ignited with lime and dissolved in nitric acid, gave $0.5820 \mathrm{grm}$. of chloride of silver.

These numbers, represented in the 100 parts, give,-

$\begin{array}{lccc} & \text { I. } & \text { II. } & \text { III. } \\ \text { Carbon . } & 30 \cdot 20 & 30 \cdot 07 & \\ \text { Hydrogen } & 0.40 & 0.28 & \\ \text { Chlorine . } & \ldots . . . & \ldots . . . & 56.20\end{array}$

Erdmann found as a mean of five combustions of the chloranil crystallized from alcohol, 30.20 per cent. carbon *. The following is the theoretical composition of the chloranil:-

$$
\begin{aligned}
& 12 \text { equivs. Carbon . . 900.00 29.33 } \\
& \text { 4. equivs. Chlorine . } \cdot 1770 \cdot 60 \quad 57 \cdot 66 \\
& \text { 4. equivs. Oxygen - } \frac{400 \cdot 00}{3070 \cdot 60} \quad \frac{13.01}{100 \cdot 00}
\end{aligned}
$$


If the formula of hydrate of phenyle and chloranil be compared, the transit of the one into the other is at once perceived.

$$
\underbrace{\mathrm{C}_{12} \mathrm{H}_{6} \mathrm{O}_{2}}_{\text {Hydrate of phenyle. }}+2 \mathrm{O}+10 \mathrm{Cl}=\underbrace{\mathrm{C}_{12} \mathrm{Cl}_{4} \mathrm{O}_{4}}_{\text {Chloranil. }}+6 \mathrm{H} \mathrm{Cl} \text {. }
$$

The foregoing equation gives the final result of the decomposition; but I must remark that another compound precedes the formation of the chloranil. If the process be interrupted when the hydrate of phenyle becomes somewhat glutinous, a solid crystalline mass will result upon cooling, in which the chloranil is enveloped by a red, tenacious, disagreeably-smelling resin, dissolving in every proportion in alcohol, and this property allows of its easy separation from the former. When the alcoholic solution of the resinous mass is submitted to distillation, what remains in the retort becomes fluid as soon as the spirit has passed off, and along with the abundant disengagement of hydrochloric acid there distils over a heavy red oil, which sometimes solidifies in the receiver, charcoal remaining in the retort.

The distillate obtained in this way dissolves in potash or ammonia. Such a solution not containing an excess of the alkali, gives with copper and silver salts the purple, violet and yellow precipitates, characteristic of chlorophenissic and chlorophenussic acids.

The circumstances under which the acid had formed made it probable that it was chlorinated chlorindoptic acid (chlorophenussic acid), particularly as it appeared collaterally with chloranil in the method originally followed by Erdmann. It might however have been chlorophenissic, or else a mixture of the two acids.

To solve this question, I decomposed the filtered potash compound of the distillate with sulphuric acid, and obtained a feebly-coloured, precipitate, which was collected on a filter, edulcorated, desiccated, and in order to remove the last traces of water, fused at a low temperature. By the distillation of this dry mass, a thick colourless oil condensed in the receiver, and also in the lower portion of the neck of the retort, which became a solid mass of a crystalline structure, possessing, with the exception of the odour, the greatest resemblance to stearic acid.

Determination of the chlorine in this compound:-

$0.5229 \mathrm{grm}$. of substance ignited with lime, \&c., gave 1.1334 grm. of chloride of silver $=\mathbf{5 3 \cdot 4 7}$ per cent. chlorine.

The preceding analysis shows the compound to be chlorophenissic acid $\mathrm{C}_{12} \mathrm{Cl}_{3} \mathrm{O}+\mathrm{HO}=53.51$ per ct. chlorine, while 
the chlorophenussic acid $\mathrm{C}_{12} \mathrm{Cl}_{5} \mathrm{O}+\mathrm{HO}=66.50$ per ct. chlorine.

In this way a large quantity of chlorophenissic acid may be readily obtained as an accompanying product in the preparation of chloranil.

From the foregoing it is seen that the chlorophenissic acid can be transformed into chloranil, of which fact I have also convinced myself by direct experiment. It occurred to me to endeavour to produce chloranil from other members of the phenyle series. By a longer or shorter action of nitric acid upon hydrate of phenyle, Laurent converted it into nitrophenessic and nitrophenissic acids (carbazotic acid). These two acids, when treated with hydrochloric acid and chlorate of potash, yield chloranil with the greatest facility. When nitrophenessic acid is taken, alcohol should be employed, on account of its insolubility in water.

Schunck* obtained some years ago, in treating aloes with nitric acid, an acid (chrysolepinic) having the same composition and the greatest similarity with carbazotic acid, but which was said to be different on account of some deviations in its compounds. It was therefore the more interesting to produce chloranil from this body, as Marchand $\uparrow$ has asserted lately that the carbazotic and the chrysolepinic acids are identical. The chrysolepinic acid is indeed transformed into chloranil. I have repeated this experiment several times with complete success, as well with a product which I prepared as with a specimen which Schunck had left in the collection of Professor Liebig.

The new researches of Gerhardt $\ddagger$ and Cahours $\S$ have shown so close a connection between the compounds of phenyle and those of salicyle, that the conversion of the latter into chloranil was to be expected. To produce this metamorphosis, it is indeed only necessary to boil salicylous acid (salicide of hydrogen), salicylic acid, or nitrosalicylic acid (indigotic or anilic acid), with hydrochloric acid and chlorate of potash. The decomposition in all these cases is very simple, the superfluous carbon escaping in the form of carbonic acid, e.g.

$$
\underbrace{\mathrm{C}_{14} \mathrm{H}_{5} \mathrm{O}_{3}+\mathrm{HO}}_{\text {Salicylous acid. }}+10 \mathrm{Cl}+4 \mathrm{O}=\underbrace{\mathrm{C}_{12} \mathrm{Cl}_{4} \mathrm{O}_{4}}_{\text {Chloranil. }}+2 \mathrm{CO}_{2}+6 \mathrm{HCl} \text {. }
$$

Although it is known that benzoic acid and salicylous acid are identical, still the former, when treated as above, does not

* Liebig's $A n n .$, Bd. xxxix. S. 7.

$\dagger$ Journ. für Prakt. Chem,, Bd. xxxii. S. 35.

+ Liebigs Ann., Bd. xlv. S. 19.

$\$$ Ann, de Chim, et de Phys., 3me S. t. x. p. 327. 
yield chloranil. This is the case also with nitrobenzoic acid, benzine, nitrobenzide, binitrobenzide, and hydruret of benzyle (oil of bitter almonds).

It yet remained to try the preparation of chloranil from salicine, the basis of all the salicyle compounds, when indeed the anticipated transformation occurred. This decomposition is readily comprehended, if it be remembered that the salicine contains the elements of 3 eqs. of salicylous acid and 10 egs. of water, e.g.

$$
\underbrace{\mathrm{C}_{42} \mathrm{H}_{28} \mathrm{O}_{22}}_{\text {Salicine. }}+24 \mathrm{Cl}+18 \mathrm{O}=\underbrace{3\left(\mathrm{C}_{22} \mathrm{Cl} \mathrm{O}_{4}\right.}_{\text {Chloranil. }})+6 \mathrm{CO}_{2}+16 \mathrm{HO}+12 \mathrm{HCl} \text {. }
$$

The salicine is, on account of its solubility in water, perhaps the fittest substance for yielding large quantities of chloranil : it is only requisite to dissolve salicine and chlorate of potash in boiling water and to add at intervals small quantities of hydrochloric acid. By degrees the mixture assumes a deep orange yellow colour, which is followed by a violent reaction; and besides the products of decomposition resulting from the chloric acid, there escapes a large portion of carbonic acid, and the surface of the liquid becomes covered with a thick layer of sulphur-yellow crystals of chloranil.

The salicine must not be treated with hydrochloric acid and then the crystals of chlorate of potash added, for the acid will transform the salicine into salicetine, which cannot be resolved into chloranil. Even by a long-continued boiling of the salicetine with the oxidizing mixture, nothing is obtained but a yellow uncrystalline mass insoluble in water and alcohol. I have made a burning of the chloranil procured from salicine and obtained the following numbers:-

$0.373 \mathrm{grm}$. of chloranil gave $0.414 \mathrm{grm}$. of carbonic acid $=30.27$ per cent.

Neither phloridzine, phloretine, cumarin, nor cinnamic acid, are transformable into chloranil. The first three furnish, by the action of chlorate of potash, yellow resinous bodies insoluble in water but soluble in alcohol, while the last is converted into a colourless oil, to which I shall recur in a future paper. It is almost superfluous to remark, that if chloranil is prepared from isatine, chlorisatine or bichlorisatine, the transformation takes place quicker and more completely by the employment of a mixture of hydrochloric acid and chlorate of potash than by conducting a stream of chlorine through the alcoholic solution, for in a few minutes the conversion of considerable quantities is effected. Anthanilic acid also naturally suffers the same decomposition.

$$
\mathrm{C}_{14} \mathrm{H}_{7} \mathrm{NO}_{4}+4 \mathrm{O}+8 \mathrm{Cl}=\mathrm{C}_{12} \mathrm{Cl}_{4} \mathrm{O}_{4}+2 \mathrm{CO}_{2}+\mathrm{NH}_{3}+4 \mathrm{HCl} \text {. }
$$


I obtained, by the direct action of the oxidizing mixture on indigo, only traces of chloranil.

In concluding, I wish to call the attention of chemists to the application of chlorate of potash as an oxidizing agent, for up to the present time it has been but seldom employed in organic chemistry, and yet the study of its action might in many cases lead to very remarkable results. I have treated kinone, which has lately become so interesting, in a similar manner to what has been stated, and found that it was transformed with the greatest facility into chloranil. In a future paper this subject will be examined more closely, and at the same time I shall throw out some hints concerning the relations of kinone to aniline, a base from which it can likewise be produced.

XXVII. Account of an Experiment on Stockholm Pitch, confirming the Viscous Theory of Glaciers. In a Letter from Prof. Gordon of Glasgow, to Prof. J. D. Forbes of Edinburgh. Communicated by Prof. J. D. Forbes in a Letter to Richard Taylor, Esq.

\section{MY DEar Sir,}

$$
\text { To Richard Taylor, Esq. }
$$

THE inclosed communication from Mr. Gordon, Professor 1 of Civil Engineering in the University of Glasgow, which he has allowed me to transmit to you for publication, will, I believe, be found interesting to your readers. The fact that pitch is susceptible of slow fuid motion, whilst it retains the character (in hand specimens) of a brittle solid, with a conchoidal fracture and glassy lustre, may assist in resolving the doubts of some impartial persons who have thought these characters in ice to be incompatible with such a motion as my theory of glaciers requires, whilst the structural bands having the frontal dip complete the analogy.

I remain, yours, very truly,

Edinburgh, February 6, 1845.

JaMES D. FonBes.

\section{To Professor Forbes.}

"When you requested me to give you a memorandum of what appeared to me to be the very glacier-like motion and appearance of Stockholm pitch flowing from a barrel, I considered my observation to have been too casual to be worth writing, and having foreseen that I could arrange an experiment at Gateshead in the beginning of the year, I delayed giving you the memorandum you wished. I had hoped to have been able to inspect and report on my experiment about this time, but I cannot go to Gateshead for some time to come, 